Educational and Psychological Studies Faculty of Education Journal Zagazig University

Vol. (36) No. (112), Part(2), July 2021

\title{
Using Communicative Approach in Developing Oral Fluency of the Secondary Stage Students
}

\author{
Radwa Mohmaed Nabil \\ A supervisor of English \\ orornabil@gmail.com
}

\begin{abstract}
:
The current study is primarily aimed to develop the EFL oral fluency skills of the secondary stage students through the communicative approach. Accomplishing thispurpose, the present study followed the pre-post, quasi- experimental-control group design. The researcher used two groups; experimental and control groups. Conducting the current research, a total of forty EFL first grade secondary stage students from AL Zankaloun secondary school, Sharkia Governorate, Egypt, were randomly assigned to two groups; twenty students for control groups and twenty for the experimental group. Generally, she managed a pre and post - testing technique for the purpose of data gathering and analysis purposes. The researcher designed EFL oral fluency test to measure EFL oral fluency skills according to their development by using the communicative approach before and after the treatment. Generally, the current study was conducted over a period of ten weeks along, with 10 sessions for applying the communicative approach on oral fluency skills. Finally, the results of the study approvedthat the communicative approach is effective in developing the EFL oral fluency of the secondary stage students, also it has a clear, strong and
\end{abstract}


noticeable impact on their motivation to speak and talk orally and fluently.

Keywords: communicative approach, EFL oral fluency skills

\section{استخداه المدخل التواصلي في تنمية الطلاقة الشفهية لدى طلاب المرحلة الثانوية}

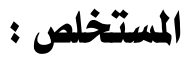

تهـدف الدراسـة الحاليـة يِّ المقـام الأول إلى تطـوير مهارات إتقـان اللغـة الإنجليزيـة كلغـة

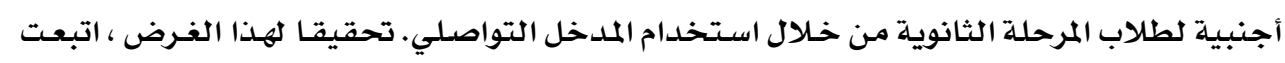

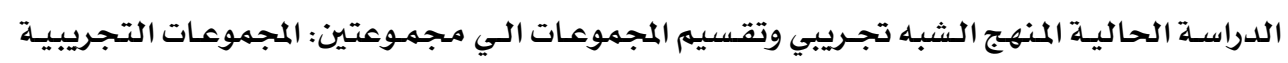

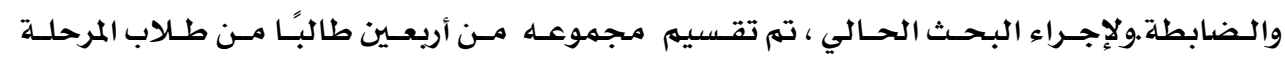

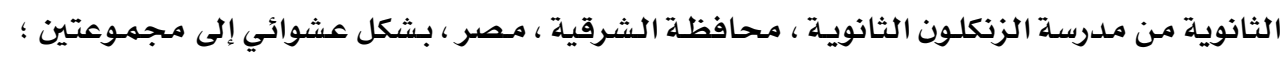

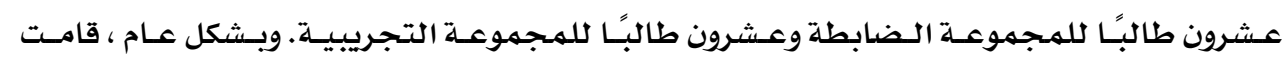

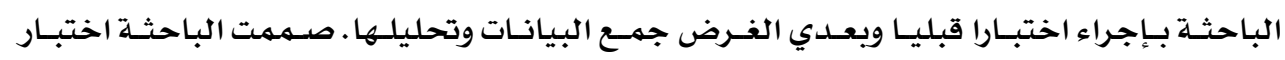

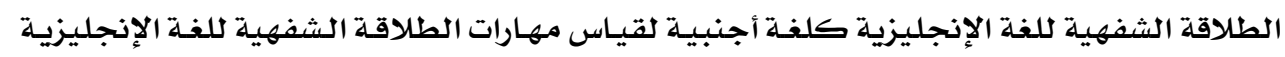

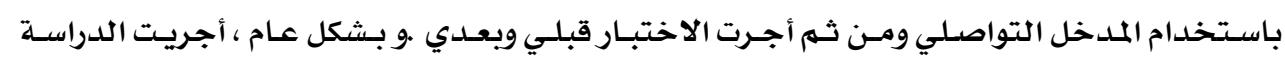

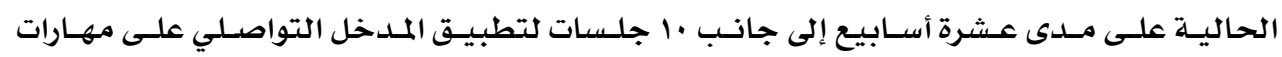

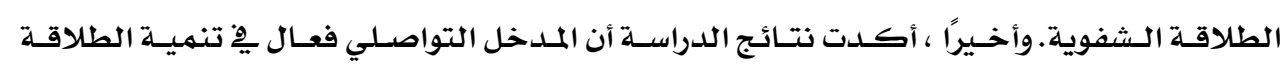

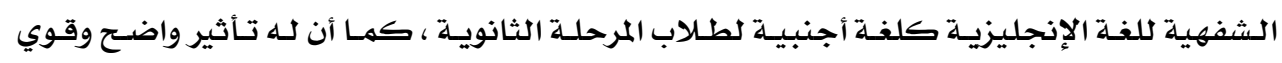

وملحوظ على دافعهم للتحدث باللغة الانجليزية والتحدث بطلاقة.

الكلمــات المفتاحيـة : المـدخل التواصـلي ، مهــارات إتقــان الطلاقــة الـشفهية للغـة

الإنجليزية كلغة أجنبية ، طلاب المرحلة الثانوية . 


\section{Introduction}

The current trends in language teaching are towards more oral work. Previously, foreign languages were taught by the way the classics are taught, that was for reading purposes, for erudition purposes. Emphasis was put on teaching structures, formal grammar. There was hardly any oral work, sometimes none at all. Questions of the relevance of the language to the student's life and interests did not arise. It was certainly the way many of us were taught languages at school. The situational language teaching in this strong emphasis is put on oral practice, grammar and sentence patterns. Drills are related to situations. For example: the teacher shows objects which are in the class: "this is a pen', the students repeat 'this is a pen': listening, choral imitation, individual imitation, question-answer drilling, systematic correction, plus follow-up reading and writing activities, these are what this method was about. There was little room for creative use of the language and for students' fluency practice.

Our students come to us not as 'empty vessels, but with a set of experiences which have influenced and still influence their behaviour. Their attitude to language and talk is heavily dependent on all that. If our students are not used to expressing themselves, to talking about their opinions and ideas in their first language it will be even more difficult to make them speak in a foreign language, because it is more threatening. To learn another language is to assent to reconsidering our relation to the world, our way of communicating with it. The learners are less to articulate, they cannot express themselves emotionally and intellectually at the same level as in their mother tongue. They very often feel foolish and vulnerable. 
Teachers in an EFL classrooms face difficulties in teaching spoken language and how to deal with oral practice and speaking tasks. The problem is observed through teaching of language in classes, in the real and current field,the recent graduates from preparatory and secondary stages and even from faculty of education and through the opinion of other teachers and supervisors. They confess that there is a great problem in the outcomes of speaking and oral fluency specially. Students can't speak well semantically and phonologically. For Gorkattseva, Gozhin \& Nagel.(2015), They pointed to the problem of enhancing fluency by using the connection between cognition and communication. For secondary stage many teachers see that it is the stage that connect the previous with the following stages. Also students of secondary stage have good amount of vocabulary and structures that could help them to master their language and show good competence of pronouncing and speaking to words.

There are strategies and activities that can help the students to jump. A lot of factors will have to be taken into account: the limitations of a syllabus, the size of the class, the age of the students, their background and expectations and their current fluency in the language. If you teach the language communicatively, you will teach the past tense When it is needed by the students to communicate, and you may teach the subjunctive only the following year. Chomsky disagreed with this view of language. According to him Language is not a habit structure but sentences are not learned by imitation and repetition but 'generated' from the 'learner's underlying competence. 
The theory behind It, is that language is not just imitation; learning a language is more than learning structures. One's task as a teacher is to facilitate the students' creative use of language and his/her ability to communicate effectively in the language. The task is vast and real communicative fluency will never be reached only through classroom practice. But classroom practice can help. Linguistic experience should be as close as possible to real life situations, should be student-centered, meaningful and relevant so as to enable the student to develop his 'competence', to use Chomsky's word.

\section{The Context of the Problem:}

The researcher noticed the low level of secondary stage students to use oral fluency in speaking English. They can't speak correctly. If they are asked to talk about a topic, they couldn't use suitable related words, utter words and sentences in a smooth sequence way to be produced as desired. The researcher conducted a pilot study to investigate the level of the first-year students in secondary school to talk about themselves orally on a sample of secondary stage students. The result of the test revealed that the students had a problem in oral fluency.

\section{The statement of the problem}

The researcher noticed according to his job,observation of students, specialists' views, and the researcher's visits to various classesinside schools in East Zagazig Zone, that there isis a low level of speaking, especially for oral fluency of secondary stage.

\section{The questions of the study:}

The present study was an attempt to answer the following main question: How could oral fluency be developed among the 
first-year secondary stage students by the use of communicative approach?

The following sub-questions could be derived from the abovementioned question?

1. What is communicative approach?

2. How effective is using communicative approach in developing oral fluency?

\section{The purpose of the study}

This study aimed at enhancing EFL first year secondary stage students' oral fluency by the use of the communicative approach.

The significance of the study: This study may help:

1* Students: To enhance students' level of oral language production.

2* Teachers: To attract students to learn easier than before, to build on different levels of students' learning to reach the desired outcome, and to benefit the teachers of other languages to use this new approach.

3*Specialists:To provide specialists with a new method to achieve the aimed outcomes.

Delimitation of the study: This study was delimited to

1- A sample of the 1 st year general secondarystage (40 students; 20 for the control group and 20 for the experimental group) because it's a year of connection between the preparatory stage 
and the university. The researcher found that they had a low achieving level of oral fluency.

\section{Study instruments:}

1- Oral fluency skills questionnaire.

2- Oral fluency test.

3- Oral fluency scoring rubric.

\section{Study Procedures:}

To achieve the aim of the study, the following procedures were adopted:

1- Reviewing the relevant literature and previous studies related to communicative approach and oral fluency.

1. Preparing a list of EFL oral fluency skills needed for the first-year secondary stage by consulting the experts to select the most appropriate ones to be developed.

2. Constructing pre post-testand submitting them to jury members to identify their importance and validity.

3. Designing a model of session based on using communicative approach intending to enhance the identified oral fluency and validating the content by submitting it to a jury of the specialist.

4. Selecting a sample of $1^{\text {st }}$-year secondary school EFL students and identifying how far is their oral fluency. 
5. Pre-administrating the oral fluency test and the to the group to identify the real standard of students concerning the previously identified skills.

6. Teaching the group by giving them tasks developed according to tasks related to the communicative approach to the previously taught topics.

7. Post-administrating the oral fluency test to the experimental sample.

8. Finding out the result of the pre-test and post-test.

9. Comparing the resultsof both administrations

10. Collecting and analyzing the data using SPSS.

11.Presenting the study results, discussion, and interpretation.

12.Providing a conclusion, recommendations, and suggestions for further researches.

\section{Definition of the terms}

A) Oral Fluency: There are many definitions for oral fluency as follow:

Rossiter et al. (2010) defined oral fluency as one of the most salient markers of proficiency in a second language. The term 'fluency' has a range of meanings, the most common of which is related to 'high proficiency,' that is, an excellent grasp of the vocabulary and grammar of a language.Also,(Derwing, Rossiter, Munro, \& Thomson et al. 2004) have shown oral 
fluency to be correlated with appropriate speech rate, distribution of silent pauses, and non-lexical fillers, such as um and uh and mean length of the run. As a word, it is the quality of being fluent (able to speak or write correctly, easily in language.( Crowther, 1997)

\section{B) Communicative approach.}

To communicate is also to know when to use, how to use or not to use the phrases or expressions; it is what (Johnson,1982) calls 'the appropriateness'. The ideal is to achieve the same flexibility, the same creativity that the native speaker possesses, using the right register in varied contexts. But operationally, the researcher defines it as the ability to negotiate, express his thought, deliver his message well and to react orally.

\section{Review of related literature and studies}

\section{The Theoretical background of communicative approach:}

The communicative Approach' originated from Chomsky's views of language. The theory behind it, is that language is not just imitation, learning a language is more than learning structures. One's task as a teacher is to facilitate the students' creative use of language and his/her ability to communicate effectively in the language.Linguistic experience should be as close as possible to real life situations, should be student-centered, meaningful and relevant so as to enable the student to develop his 'competence', to use Chomsky's word. The Communicative Approach requires that students should be helped to become more independent and daring in their use of the foreign language. They should be encouraged to try out the 
language. If they do not try it out in the classroom they will have a lot of difficulties in doing it in the real world.

Wilkins (1972)tookthe example of swimming: you can learn all the strokes out of the water and become very competent in theory but to jump in the pool and swim is another matter. When will you dare to jump? How will you be encouraged to do so? There are strategies and activities that can help the students to jump. A lot of factors will have to be taken into account: the limitations of a syllabus, the size of the class, the age of the students, their background and expectations and their current fluency in the language. But there are some general ideas which can be applied in most cases. What and how should we teach? Grammar, for example, will have to be taught, otherwise nearnative fluency will never be possible and sometimes communication would be impossible. But how can you do this in a meaningful context? If you follow the traditional GrammarTranslation method, you teach all the tenses one after the other, including conditional and subjunctive, even if you do not use them very often. If you teach the language communicatively you will teach the past tense when it is needed by the students to communicate. The content of the material used for teaching is an" important element as well. It has to be real and relevant to the students' life and interests. The more students are interested in an activity in the target language, the more they feel the desire to communicate in the language.

There have been criticisms or worries about the 'Communicative Approach'. With more emphasis on language use in the classroom, there will be more students' errors. Even if we agree that fluency has to be encouraged, should accuracy be encouraged or shall we forget about it?. There isn't a 
contradiction between the notions of accuracy and fluency. We have to try to develop accuracy as well as fluency but not necessarily at the same time. When students are engaged in a creative activity, the aim of the activity is to communicate for a purpose. But the teacher could make notes of the most frequent mistakes rind at another time introduce the relevant grammar points. Other activities could be more teacher-centered and focused on accuracy. Then feedback should be systemically provided.

\subsubsection{0ral Fluency}

The researcher shows the importance of speaking and oral fluency. It is important to mention the difference between speaking and fluency. Speaking is the main skill; it includes all the levels of oral communication and all the stages of that process. On the other hand, fluency is a sub-skill and implies how easy a foreign language learner can express himself without having to stop to think about words Studies in language learning have addressed the necessity of classroom interaction or students' oral participation in class. The relation between speaking and fluency has been studied by some authors who stated that a good fluency does not mean that a person speaks a language but indicates better communication and transmission of ideas conducing to better proficiency. For example, a student in the different stages of his learning process could develop the necessary vocabulary to communicate in another language. Then, that student is confronted with different scenarios to apply his new vocabulary, and he could get his communications to be fulfilled, but fluency will determine his ability to be clear and to have a good reception by the recipient. However, getting students to respond in a language classroom, especially a 
foreign language class is a problem that most language teachers face. This study aims to suggestremedies to language learners through communicative approach.

In Xiao-yupaper(2016), He discussed the concept of oral fluency and some factors which influence students' oral fluency, analyses the data from first-year English majors in USST ( The University of Shanghai for Science and Technology). He designed some effective ways to provide every chance to "force" students to speak English and to improve the students" oral fluency effectively. The researchers have attempted to define fluency from different perspectives and have stated many aspects of the concept, which led to different opinions of factors influencing oral fluency. Semantic, articulate, and lexicalsyntactic elements are very important factors to influence oral fluency.

Huang and Van (1987) suggested that memorizing chunks of language, phrases, or prefabricated routines may help to get conversations going and to build up confidence in speaking. He discussed if students want to reach the goal of oral fluency, they must make full use of the oral class. He used the 4/3/2 technique. Learners delivered a four-minute talk on his familiar topic to a partner. Then they changed partners and gave the same talk to a different partner but within three minutes. And finally, they changed partners again and delivered the same talk within a two-minute time limit. , each speaker had to practice the same talk three times to three different listeners with a decrease in time. Each of these three features, a changing audience, repetition, and decreasing time amount for delivery, made an important contribution to the development of oral fluency. . After experiencing the 4/3/2 practicing, the student 
will speak more fluently and more confidently. Teaching English can be very interesting. Successful teaching involves an increased awareness of what the teacher should do now and how to make a little change from the traditional way of teaching. Different English class design mentioned above aims to offer a brand new method of all-around oral training. These game-like activities will be popular as they are fresh for students and feasible for teachers. It does not need special facilities but has the following advantages: (1) Students have many more opportunities to speak in any kind of English classes; (2) feedback between student-student and teacher-student increases greatly; and (3) harmonious and relaxed class will motivate students' involvement. All these provide guarantees for improving oral fluency.

In some ways, research into second/foreign language learning strategies made some in the last decade to identify specific techniques and strategies which are believed to account for successful learning. From these studies, several inventories of good learner strategies have been proposed. These inventories provide insights into some of the common characteristics of successful learning which have greatly enriched our understanding of the learner. Studies of learning strategies and techniques have also offered practical implications for language teaching and learning. Huang \& Van. (1987) have a deepened understanding of the second/foreign language learning processes and the learner at different age and maturity levels, and different levels of proficiency. They also have offered practical implications for learning oral language through further investigation and experimentation. 
Sixty of the approximately 120 graduating students were randomly selected. The age range was 19-25 years of age (with an average age of 21). Three instruments were used to gather the data for this study: (1) a test of oral communicative ability; (2) a questionnaire on learner strategies; and (3) an in-depth interview. The test of oral communicative ability in English (Royal Society of Arts Examination Board) followed an interview format and included tasks as describing one's home town and giving newly arrived foreign teachers some information about the Foreign Language Institute. The interviewers used similar criteria for evaluating the students' oral performance. He also used learning strategies formal practice, functional practice, and monitoring.

Formal practice included such activities as listening to and doing pattern drills, listening to improve pronunciation, memorizing and reciting texts, imitating, re-telling stories, reading aloud, and reading to learn vocabulary items or grammatical structures. Functional practice included activities that mainly focused on using the language for communication, such as speaking with other students and native speakers, listening and reading for comprehension, attending lectures, watching films and TV programs, and thinking or talking to oneself in English. Monitoring as a strategy refers to the efforts made by the learner to pay attention to the use of linguistic forms and modify language responses.

Functional practice included activities, focused on using the language for communication, such as speaking with other students and native speakers, listening and reading for comprehension, attending lectures, watching films and TV programs, and thinking or talking to oneself in English. 
Educational and Psychological Studies Faculty of Education Journal Zagazig University Vol. (36) No. (112), Part(2), July 2021

2. The correlation between communicative approach and oral fluency.

From the researcher teaching experience and supervision, communicative approach is an example of approach which can encourage oral fluency. If we want our students to talk they must feel at ease with us and with each other. In general, classes should have a good, relaxed atmosphere, so teacher and students can communicate. However there are some differences between adult education students and younger full-time students. The younger students did not hesitate to comment freely on each other's contributions. Other students very rarely did so. There are some strategies that could help in improving oral fluency:

\section{1-Small-group-activities}

Fysh (1990) stated that Students speak more easily in front of a small group than in front of the whole class, they feel freer to try out, to experiment with the language and in this way they can improve their fluency and their self-confidence. Group work is a strategy, but not an activity in itself. Different types of activities can be carried out in groups. It could be a discussion or a task with reporting back to the whole class afterwards. These activities have to be meaningful as well; real information must be exchanged: For instance you can use gap-filling exercises, which could be two different cartoons-with incomplete information; to make it complete the students have to ask each other questions and be able to communicate in a real way.

\section{2- Whole-class activity}

A lot of whole-class activities aim at improving the students' oral fluency as well. Discussions and debates, games, 
simulation and role-play can make it easierDiscussions and debates worked well and were enjoyed by students with a good level of fluency.

\section{3-Individual - activities}

Each student has to introduce one event he knows about in his month; the others ask questions about it, ask for details, circumstances, etc. Everybody takes it in turn.As 'homework' the students are asked to fill in the gaps. When teacher asks them about it, they always react positively: they are all competing to give their answers, they don't not wait to be asked; everybody wants to talk and they are obviously enjoying themselves very much.

\section{4-The use of questioning}

Fysh (1990) continued in his research to explore some communicative approach strategies. The last one is (questioning). It takes place in all classes observed; in general more questions come from the teacher than from the students. The questions were usually open or closed. Most questions about facts are necessary to check the Students' understanding of a written or spoken texts. There cannot be many questions about opinions, except 'closed' opinions, because it is very difficult initially to express opinions in a foreign language.

\section{4-The study hypotheses}

1-There will be a statistically significant difference between the mean scores of the experimental group, and those of the control group in the post administration of the EFL oral fluency skills test in favor of the experimental group. 
2-There will be a statistically significant difference between the mean scores of the experimental group in their performance in the pre and post administrations of the EFL oral fluency skills test in favor of the post-administration.

3-The communicative approach would be effective in developing the first-year secondary stage students' EFL oral fluency skills.

\section{Study method and procedures}

\section{1-Design of the study}

The Present study followed the quasi-experimental design in which the participants were randomly selected and designed for the experimental and control groups. The experimental group students were taught by administrating the communicative approach for developing their oral fluency. On the other hand, control group students were taught by the regular instruction. Data were obtained by using an EFL oral fluency test. Data were statistically analyzed using the SPSS program.

\section{2- Participation of the study}

The participants of the study were the first-year secondary stage students of Al Zankaloun secondary school in the first term of the scholastic year 2020/2021. The number of the participants in the current study was 40 female students who were chosen randomly. They were students from grade one, 20 students for the experimental group and 20 for the control one. All the participants' ages ranged from 15 to 16 years old. They had weaknesses in speaking generally and oral fluency specially. 


\section{3- The instruments of the study}

- The EFL oral fluency skills test:For designing the oral fluency skills test, an EFL oral fluency questionnaire was a prerequisite. For grading the EFL oral fluency test, an EFL oral fluency skills rubric was a post requisite.

A- The EFL oral fluency skills questionnaire.

B- The EFL oral fluency test.

C- The EFL oral fluency rubric.

\section{A-The EFL oral fluency skills questionnaire}

\section{1-Purpose}

The researcher prepared the oral fluency skills questionnaire that aimed at identifying the most important oral fluency skills for secondary school students. The EFL oral fluency skills questionnaire is a pre-requisite for the EFL oral fluency test.

\section{2-Description}

The first form of the questionnaire consisted of six main skills of oral fluency, which are listening, expressions and volume, phrasing, smoothness, pace (rate), and finally accuracy and fluency. These main skills were classified into twenty-five oral fluency sub-skills. Each level of importance was given an estimated value: (very important) took (three), (important) took (two) and (less important) took (one). After analyzing the jury members' responses, the researcher selected the skills that were agreed upon for at least $90 \%$ by the jury members.

\section{3-Sources}

The items of oral fluency skills included in the 
questionnaire were derived from the following:

- The student's book New Hello English for the first year of the secondary stage.

- The teacher's guide for the student's book.

- The main objectives of teaching speaking skills and their levels in the first year of the secondary stage.

- Surveying relevant studies concerned with oral fluency such as (Anne Bayetto, 2013;Xiao-yun,2016) and other searches from the internet.

- The opinions of professors and specialists in the TEFL field.

\section{4-Validity}

The oral fluency skills questionnaire was submitted to a panel of jury members who are professors and specialists in the field of EFL teaching. Those jury members were requested to determine the appropriateness of the questionnaire items for the first year secondary school students, determine the degree of importance of each item in the questionnaire; very important (3); to some extent important (2) or less important (1), and to indicate if any items needed to be omitted, added, or modified. The questionnaire was considered valid.

5- Results

The modifications suggested by the jury members were as follows:

- Reducing and omitting some phrases of the total number of skills. 
- Changing" important "to be "some extent important".

Therefore, nineteen skills were selected to be developed in the present study. These skills can be shown as follows:

A-Expression and volume component skills such as:

1 -speak in a quiet voice to get words out

2-utter sounds naturally, but he/she doesn't always speak like talking to a friend.

3 -sound with varied volume

4-talk to a friend with a voice matching the situations.

B-Phrasing component skills such as:

5 -speak word by word in a monotone voice.

6-speak in two or three-word phrases adhering to punctuation, stress, and intonation.

7-speak with mid-sentence pauses and some chopping with effort.

8-speak with longer good phrases adhering to punctuation stress and intonation.

C-Smoothness component skills such as:

9-speak smoothly with some breaks, but self-correct with difficultwords /sentences

10-Speak smoothly without any breaks and with self-correction.

D-Pace (rate) component skills such as:

11-speak fast with less effort and short time.

12-pronounce fluidly. 
E-Accuracy and fluency component skills such as:

13-express the situation exactly.

14-deliver the meaning of the message thoroughly with no effort as before.

15- feel comfortable during speech.

16-Shorten time of thinking about words of speech.

17-use correct structures of sentences.

18-master the utterances of words.

19- Pronounce words correctly.

\section{B-The EFL oral fluency test}

\section{1-Purpose}

The EFL oral fluency test was used as a pre post-test for evaluating EFL first-year secondary school students' oral fluency skills. It was pre-used to determine the actual standard of the EFL secondary school students' oral fluency skills before the administration of the communicative approach. As a posttest. It was used to explore the effectiveness of using the communicative approach in developing students' oral fluency skills.

2-Description

The EFL oral fluency test consists of five questions about culture.

1-Asking students: Which country have you visited?

2-Talk about the most common places there? 
3-What are their customs?

4-What are their people folk?

5-Talk about the most of their culture you have admired?

3-Source

The oral fluency test was designed in the light of oral fluency skills determined by the result of the oral fluency questionnaire. Moreover, some of the oral fluency skills test questions, included in the test, were adapted from the students' book, Hello English for the first year of secondary stage.

\section{4-Validity}

For measuring the validity of the content of the oral fluency skills test, It was submitted to a group of EFL professors and specialists to evaluate its appropriateness to the first-year secondary school students. Moreover, the jury members were also requested to determine if the test items are sufficient to measure the intended skills. They were also asked to determine the validity of the test as a whole in terms of content, correctness, and level of comprehensibility.

\section{5-Reliability}

The oral fluency test was administrated to twenty students in grade two secondary stage who are not included in the participating groups. The reliability of the test was measured by using different methods. The first one was Alpha -Cronbach way. The results revealed that the value of Alpha was (0.750) which indicates a statistically reliable value. The researcher also used a split-half technique where (0.832) for Spearman-Brown Coefficient and (0.831) for Guttman Spilt-Half Coefficient which indicates a statistically reliable value. 


\section{7-Piloting}

The EFL oral fluency skills test was administrated to a randomly selected group of $20 \mathrm{EFL}$ students in the first year secondary stage, at Al Zankaloun secondary school, Sharkia governorate, Egypt. The test was piloted to investigate its suitability for the students; the simplicity/difficulty of questions of the test and the suitability of time needed for administrating the test.

\section{8-Timing}

Twenty students, apart from the participants of the study (grade two students), were randomly selected from $\mathrm{Al}$ Zankaloun secondary school, for timing the oral fluency test. The test was estimated that a period of (45 minutes) would provide ample time for the students to answer the test questions. No extra time was needed to complete the task.

\section{9-Scoring}

The total score of the test was twenty-five marks. Scoring the EFL oral fluency skills test was run according to a rubric designed by the researcher for evaluating the participants' mastery of the EFL oral fluency skills in the pre-post oral fluency test.

\section{0-Administration}

The test was pre administrated to the experimental and control groups in October 2020, then the experiment group. It was post administrated at the last of December 2020. Both conditions were relatively the same in terms of place and time. During the test administration, the researcher clarified the content of the test and its directions. The researcher ensured that 
all the participants had understood the required points from them.

\section{C-The EFL oral fluency skills rubric}

\section{1-Purpose}

The EFL oral fluency rubric was used for scoring the EFL oral fluency test. It's a post requisite to the EFL oral fluency skills test.

\section{2-Description}

The EFL oral fluency skills rubric consists of five rating scales for the different components of oral fluency skills (expression and volume, phrasing, smoothing, pace, accuracy and fluency). The five rating scales according to scores and marks ( 5 the highest mark, 4, 3, 2, and 1 the lowest mark). The scorer should give each student a suitable mark according to her level shown in the rubric.

\section{3-Sources}

The EFL oral fluency skills rubric was constructed by the researcher according to reading for some literature and in the light of the levels of the independent variable (communicative approach).

\section{4-Validity}

To ensure that the oral fluency rubric is valid for its purpose, It was submitted to a panel of jury members who are professors and specialists in the field of teaching English as a foreign language. The jury members were requested to determine the rubric's validity according to its suitability for the students of the preparatory stage and measuring the targeted 
EFL oral fluency skills. The jury members were also requested to determine the appropriateness of each rating scale of the rubric.

\subsection{2-The content of the communicative approach}

The content of the communicative approach was adapted from the student's book and teachers' guide for the first year secondary school. The researcher made use of the student. He depended on unit 5 "Holidays". The unit consists of six lessons+ one lesson as a review. The lessons contain listening and speaking tasks. It includes many activities and strategies like working in pairs and groups, talking about the pictures, and asking questions.

\subsection{3-The principles}

For achieving the main aims of the study:

-Providing students with introductory time about how to try to improve their oral fluency for helping them to talk and speak later on. The time was essential to give them the important information about the session which was needed to teach them how to improve their oral fluency by using the (communicative approach).

-Some activities and tasks were prepared to suit the intended oral fluency skills and to consider the students' academic levels and their individual differences.

\subsection{4-Administration}

The oral fluency skills testwas pre administrated to the participants for both (control and experimental) groups. The sessions lasted for one term 2020. The sessions lasted for ten 
sessions to ten weeks for the experimental group.Sessions took 45 minutes for administration.

\section{$\underline{\text { Results and discussion }}$}

\section{1-Pre Test statistics:}

\section{(EFL oral fluency skills)}

Before experimentation, both groups (control and experimental) were pre-tested using an independent t-test to make sure that both groups were equal in their EFL oral fluency skills.

$$
\text { Table(1) }
$$

Pre t-testEFL oral fluency skills for the control and the experimental groups in the EFL oral fluency skills test.

\begin{tabular}{|l|l|l|l|l|l|l|l|}
\hline Skill & Group & N & M & S.D & df & $\begin{array}{l}\text { t- } \\
\text { value }\end{array}$ & Sig \\
\hline $\begin{array}{l}\text { Overall } \\
\text { EFL oral } \\
\text { fluency } \\
\text { skills test }\end{array}$ & Control & 20 & 7.60 & 1.84 & & & \\
\cline { 2 - 8 } & Experimental & 20 & 7.55 & 1.70 & 38 & .089 & $.929^{*}$ \\
\hline
\end{tabular}

*Non-significant.

The pre-testing results in table (1) show that the t-value (.929) is not significant at the level of 0.01 . So, there was no significant difference between the control and the experimental group in Overall EFL oral fluency skills in the pre-test.

\section{Post-Test Statistics:}

To determine whether students' EFL oral fluency skills and Self-confidence improved after implementing the experimental 
treatment using the communicative, the hypotheses of the study were tested by using the Statistical Package for Social Sciences (SPSS version 26) Program.

\section{Hypothesis (1):}

1-There will be a statistically significant difference between the mean scores of the experimental group, and those of the control group in the post administration of the EFL oral fluency skills test in favor of the experimental group.

\section{Table (2)}

Post $t$-test results of the control and the experimental groups in expressions and volumes, Phrasing, Smoothness, pace (rate), fluency and accuracy, and Overall EFL oral fluency skills

\begin{tabular}{|c|c|c|c|c|c|c|c|}
\hline Skill & Group & N & M & S.D & $\begin{array}{c}\text { D. } \\
\text { f }\end{array}$ & $\begin{array}{c}\text { t- } \\
\text { value }\end{array}$ & sig \\
\hline $\begin{array}{c}\text { Overall EFL } \\
\text { oral } \\
\text { fluency } \\
\text { skills test }\end{array}$ & Control & 20 & 7.56 & 1.78 & & & \\
\cline { 2 - 7 } & experimental & 20 & 22.80 & 1.73 & & 27.21 & 0.000 \\
\hline
\end{tabular}

The table above indicates that the mean scores of the experimental group students are higher than those of the control group in the Overall EFL oral fluency skills, where t-value is, (27.21) for overall oral fluency skills. Therefore, this hypothesis was confirmed. These differences can be attributed to the communicative approach.

\section{Hypothesis (2):}


2-There will be a statistically significant difference between the mean scores of the experimental group in their performance in the pre and post administrations of the EFL oral fluency skills test in favor of the post-To verify this hypothesis, the researcher used the paired sample t-test to compare the mean scores of the experimental group who used the communicative approach in the pre and post-test. The following table includes the results.

\section{Table (3)}

Post t-test results of the experimental group pre and post in expressions and volumes, Phrasing, Smoothness, pace rate),fluency and accuracy, and Overall EFL oral fluency skills.

\begin{tabular}{|l|l|l|l|l|l|l|l|}
\hline Skill & Group & N & M & S.D & $\begin{array}{l}\text { D. } \\
\text { f }\end{array}$ & $\begin{array}{l}\text { sig } \\
\text { value }\end{array}$ \\
\hline $\begin{array}{l}\text { Overall EFL } \\
\text { oral fluency } \\
\text { skills test }\end{array}$ & Pre & 20 & 7.55 & 1.70 & & 32.10 & 0.000 \\
\cline { 2 - 6 } & Post & 20 & 22.80 & 1.73 & & & \\
\hline
\end{tabular}

The table above indicates that the mean scores of the experimental group students are higher than those of the control group in the Overall EFL oral fluency skills, where t-value is, (32.10) for overall oral fluency skills, (20.67).Therefore, this hypothesis was confirmed. These differences can be attributed to the communicative approach.

\section{Hypothesis (3)}

3-The communicative approach would be effective in developing the first-year preparatory stage students' EFL oral fluency skills. 
To verify this hypothesis, the researcher calculated the effect size by using the paired sample t-test to compare the scores of the experimental group in the students' EFL oral fluency skills in the pre and the post-test using Cohen's formula.

$$
\begin{aligned}
& \text { Cohen's formula }=\eta^{2}=\frac{t 2^{2}}{t}{ }_{2}^{2}+d f \\
& \sqrt{2} \frac{\eta^{2}}{1} \\
& \mathrm{~d}=\mathrm{Es}=
\end{aligned}
$$

Where $\eta^{2}=$ Etasquare

$\mathrm{T}=\mathrm{t}$ test valueDf $=$ degree of freedomD $=\mathrm{Es}=$ effect size

Table (4)

The referential framework for identifying the effect size for the T- test value.

\begin{tabular}{|l|l|}
\hline Effect size & Interpretations \\
\hline From 0.2 till less than 0.5 & Small \\
\hline From 0.5 till less than 0.8 & Medium \\
\hline From 0.8 or more & Large \\
\hline
\end{tabular}




\section{Table (5)}

The effect size of the experimental group in EFL oral fluency skills as a whole in the pre and the post-test.

\begin{tabular}{|l|l|l|l|l|l|l|l|}
\hline Skill & Test & N & M & S.D & $\begin{array}{l}\text { t- } \\
\text { value }\end{array}$ & $\begin{array}{l}\text { Eta } \\
\text { square }\end{array}$ & $\begin{array}{l}\text { Effect } \\
\text { size }\end{array}$ \\
\hline $\begin{array}{l}\text { Overall EFL } \\
\text { oral fluency } \\
\text { skills test }\end{array}$ & Pre & 20 & 7.55 & 1.70 & 32.10 & .956 & 4.661 \\
\cline { 2 - 5 } & Post & 20 & 22.80 & 1.73 & & & Large \\
\hline
\end{tabular}

Table (5) indicates that the effect size of the experimental group students in the post-test are greater and higher than those of the pre-scores in Overall EFL oral fluency skills, where the effect size is (4.661) for Overall EFL oral fluency skills. According to the findings of Cohen's formula and the interpretations of the effect size, the percentage 4.661 indicated that the communicative approach had an effect on improving the students' EFL oral fluency skills.

\section{.2- Discussion of the results}

These significant improvements in the experimental group's oral fluency attributed to many reasons related to the nature of the communicative approach and its stages which can be shown as follows:

1-Providing participants with different tasks and activities that enable them to get more exposure to the oral fluency skills. The carefully selected tasks were suitable for their academic levels and the individual differences. 
2-The communicative approach provided the participants with a set of instructions that enabled them to organize their carrying out the required tasks.

3-Dividing participants into pairs and groups first encouraged them to exchange ideas, to overcome their fears then to speak fluently and individually at last.

4-Providing the participants with the facility to express their outcomes frankly in "entry and exit card for student's selfreflection", was successful in learning from their mistakes and trying to avoid them in the following stages.

5-Presenting the oral fluency task individually helped the other participant's colleagues to acquire some more information and create more. In addition, it encouraged them to do the same and have more and more self-confidence. They were a role model for each other.

\section{The conclusion, recommendations, suggestions of the study}

\section{1-Conclusions}

Using the communicative approach approved its effectiveness in developing EFL students' oral fluency. The students' skills of oral fluency as: expressions and volume, phrasing, smoothness, pace (rate), fluency and accuracy have been developed. Moreover, the students also mastered the components of each skill represented in nineteen sub-skills as: get out words, utter sounds naturally, sounds with varied volume, speak using phrases; punctuation; stress and intonation, speak using sentences correctly, use a short time, pronounce fluidly, express the situation exactly and deliver the meaning of 
message comfortably. In addition, the cohesion and coherence of phrases and sentences have been developed through the repeated use of the same topic. They shortened the time of thinking because of practicing speaking through the sessions of the same topic.

\section{2-Recommendations}

1-The educators should make use of the communicative approach to develop students' oral fluency.

2-The communicative approach creates an opportunity for students to practise the topic severally and avoid mistakes, so using miscellaneous activities, audios, pictures, and flashcards could be helpful in these stages.

3-Encouraging students in each stage is very important to build on the previous step and to accomplish the following ones.

4-Encouraging students to think and add some more words and sentences are recommended. The educator must dare to come out of their traditional shells and give up the spoon feed teaching methods.

5-Curricula designers should design more effective English language courses depend on the communicative, using several activities.

\section{3-Suggestions for further research}

1-Many future researches can be conducted to explore the effectiveness of using the communicative approach in developing the EFL students' skills in different areas not just only in oral fluency but also in speaking, oral communication. Reading, writing, and listening. 
2-More experimentation is needed to investigate the effectiveness of using communicative approach in developing oral fluency in different educational stages such as primary, secondary, and university stages.

3-Many researches can be conducted to determine the relationship between using communicative approach and other psychological factors such as anxiety, trust, success, failure, attribution, and creativity.

\section{$\underline{\text { References }}$}

Anne Bayetto(2013):Fluency: Speed (SA) Newsletter, University School of Education, 11-13.

Crowther.J. ( 1997).Oxford Advanced Learners Dictionary: fifth edition,England:Oxford University Press.

Gorkattseva .E ,Gozhina .A , Nagelb .O ( 2015). Enhancing Oral fluency as a Linguodidactic issue.Linguistic and Cultural Studies: Traditions and Innovation.Tomask, Russaia : National Research TomskState University 141-147.

Fatma T. G. (2014). Speaking problems of $9^{\text {th }}$ grade high school Turkish learners of L2 English and possible reasons for those problems: Exploring the teachers and students' perspectives.Procedia -Social and Behavioural Sciences. 1-6

Fysh. M.C.(1990).An investigation into methods of_developing oral fluency in foreign language teaching: The Vocational Aspect of Education. 42-111, 19-23.DOI: $10.1080 / 13636829008619466$ To link to this article: https://doi.org/10.1080/13636829008619466 
Gillis, G. (2013).The Importance of Speaking Skills: retrieved from: http://www.geraldgillis.com/importance-speakingskills/

Huang, X. H., \& Van Naerssen, M. (1987):Learning strategies for oral communication: Applied Linguistics. TESOL ewsletter. 8(3). 287-307.

Johnson. K. (1982).Communicative Syllabus Design and Methodology: Pergamon Press. 12

Rossiter .J.M, Derwing. M.T , Manimtim. G.L \&Thomson. I.R (2010):The Culture Assimilator An Approach to CrossCultural Training:New York: Journal of Applied Psychology. 122

Wilkins, D. A. (1974).Linguistics in Language Teaching: Edward Arnold, of Applied Psychology .New York.1-22

Xiao-yun. J (2016):English Class Design to Improve Students' Oral Fluency: China Sino-US English Teaching.Shanghai: University of Shanghai for Science and Technology. 8(13). 622626 
Appendices

\section{Description of the communicative approach}

Throughout passing some activities and strategies like pair, group work, and open discussion in each session, the teacher could achieve the desired objectives of the course .According to the progression of students' levels in oral performance,the utterance of words should be increased, time and effort decreased.During this process of communicative approach, students will enhance their abilities to overcome their problems of speaking like shyness, mispronouncing of words, choosing appropriate words in situations, and chopping in talking.

\section{The introductory session for using the communicative approach in Oral Fluency.}

1-The researcher welcomes students and expresses her gratitude for them to participate in this experiment, The researcher tells them that the session will last for 45 minutes using the communicative approach for improving their oral fluency'

2-There is a teacher as a co-assistant, co-rater and observer who could help the researcher in proceeding her steps. She will be the teacher of the class.

3-Showing the teacher how the researcher introduces the communicative approach.

4-The teacher divides students into 4 groups. Each group has 5 participants.

a. The researcher gives them a task to be done in each stage. 
b. First each student follows the instructions, then does what is asked from him to do.

5-The teacher of class will notice the students' interaction and performance at each stage/level.

\section{$\underline{\text { A model for a session }}$}

Objectives: By the end of this session, students will be able to:

1-speak using words which express about technology.

2-utter words and sounds with varied volumes and articulation.

\section{Learning outcomes:}

This session is intended to be the first level of SOLO

Taxonomy, so students could speak and get out some unconnected words with utterances Type of activities: individuals and group work.

\section{Material needed:}

Text book - cards for different cultures - student book

Time: 45 minutes

Participants: 20 participants

Procedures: 1 -The researcher divides students into 4 groups. Each group contains 5 participants. The researcher reads the instructions to students, then he begins the task by giving them cards for items of different cultures. The students are asked to choose one of those cards to stick in their entry reflection, trying to write some words they know about the topic. (5 minutes) 
Educational and Psychological Studies Faculty of Education Journal Zagazig University Vol. (36) No. (112), Part(2), July 2021

After writing their knowledge in their entry reflection, they can talk to each other about their knowledge. (5 minutes).
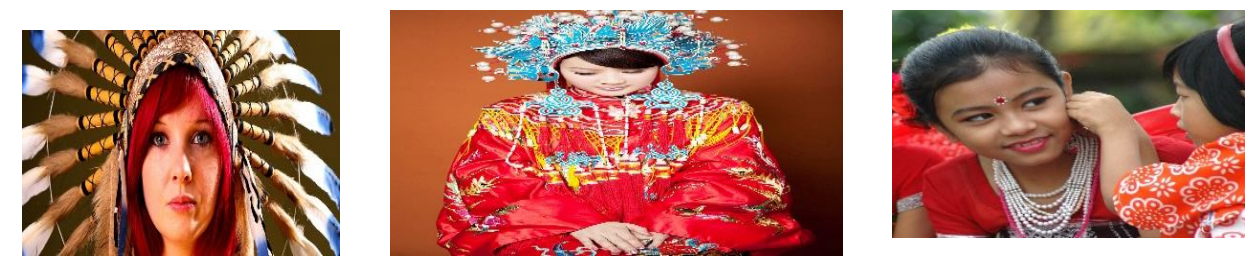

2-The researcher asks each one to talk individually about his card that he has chosen using the words he knows in maximum 5 minutes.

3-The researcher doesn't interrupt their talking, but noticing their levels of oral performance (words, utterances).

The scoring sheet for the EFL Oral Fluency

\begin{tabular}{|c|c|c|c|c|c|c|c|c|}
\hline \multirow[t]{2}{*}{$\begin{array}{c}\text { Question } \\
\text { No. }\end{array}$} & \multirow[t]{2}{*}{$\begin{array}{l}\text { Oral } \\
\text { fluency } \\
\text { skills }\end{array}$} & & \multicolumn{5}{|c|}{$\begin{array}{c}\text { Scores of the five scales in } \\
\text { the } \\
\text { rubric }\end{array}$} & \multirow{2}{*}{ 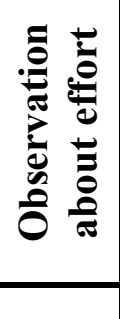 } \\
\hline & & & 5 & 4 & 3 & 2 & 1 & \\
\hline \multirow{3}{*}{ - } & \multirow{3}{*}{ 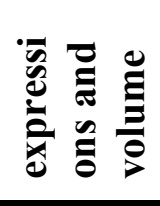 } & time & & & & & & \\
\hline & & $\begin{array}{l}\text { Number } \\
\text { of words }\end{array}$ & & & & & & \\
\hline & & marks & & & & & & \\
\hline \multirow{3}{*}{ 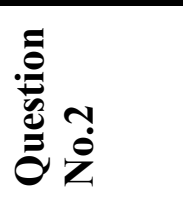 } & \multirow{3}{*}{ 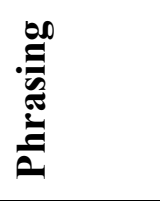 } & time & & & & & & \\
\hline & & $\begin{array}{l}\text { Number } \\
\text { of words }\end{array}$ & & & & & & \\
\hline & & marks & & & & & & \\
\hline \multirow{3}{*}{ 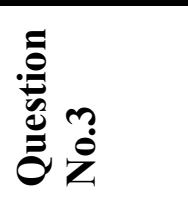 } & \multirow{3}{*}{ 苨 } & time & & & & & & \\
\hline & & $\begin{array}{l}\text { Number } \\
\text { of words }\end{array}$ & & & & & & \\
\hline & & marks & & & & & & \\
\hline
\end{tabular}

$-415-$ 


\begin{tabular}{|c|c|c|c|c|c|c|c|c|}
\hline \multirow[t]{2}{*}{$\begin{array}{c}\text { Question } \\
\text { No. }\end{array}$} & \multirow[t]{2}{*}{$\begin{array}{l}\text { Oral } \\
\text { fluency } \\
\text { skills }\end{array}$} & & \multicolumn{5}{|c|}{$\begin{array}{c}\text { Scores of the five scales in } \\
\text { the } \\
\text { rubric }\end{array}$} & \multirow[t]{2}{*}{ 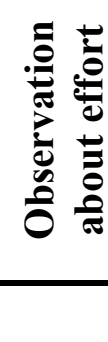 } \\
\hline & & & 5 & 4 & 3 & 2 & 1 & \\
\hline \multirow{3}{*}{ 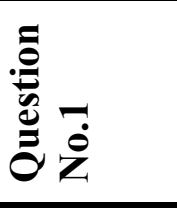 } & \multirow{3}{*}{ 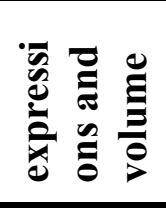 } & time & & & & & & \\
\hline & & $\begin{array}{l}\text { Number } \\
\text { of words }\end{array}$ & & & & & & \\
\hline & & marks & & & & & & \\
\hline \multirow{3}{*}{ 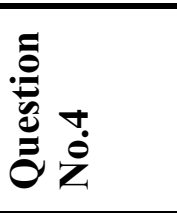 } & \multirow{3}{*}{ 导 } & time & & & & & & \\
\hline & & $\begin{array}{l}\text { Number } \\
\text { of words }\end{array}$ & & & & & & \\
\hline & & marks & & & & & & \\
\hline \multirow{3}{*}{ 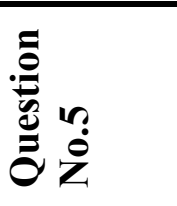 } & \multirow{3}{*}{ 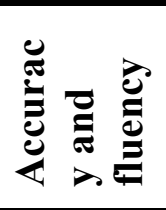 } & time & & & & & & \\
\hline & & $\begin{array}{l}\text { Number } \\
\text { of words }\end{array}$ & & & & & & \\
\hline & & marks & & & & & & \\
\hline
\end{tabular}

